\title{
Blocking the RAAS at different levels: an update on the use of the direct renin inhibitors alone and in combination
}

This article was published in the following Dove Press journal:

Vascular Health and Risk Management

26 June 2010

Number of times this article has been viewed

\author{
Francesca Cagnoni' \\ Christian Achiri Ngu Njwe' \\ Augusto Zaninelli ${ }^{4}$ \\ Alessandra Rossi Ricci' \\ Diletta Daffra ${ }^{2}$ \\ Antonio D'Ospina' \\ Paola Preti ${ }^{3}$ \\ Maurizio Destro' \\ 'Internal Medicine, Ospedale Unificato \\ Broni-Stradella, Stradella (PV), Italy; \\ ${ }^{2}$ Internal Medicine, S.S. Annunziata \\ Hospital, Varzi (PV), Italy; ${ }^{3}$ nternal \\ Medicine, University of Pavia, Pavia, \\ Italy; ${ }^{4}$ School of Medicine, University \\ of Florence, Florence, Italy
}

Correspondence: Francesca Cagnoni Hospital of Broni-Stradella, Via Achilli 3, 27049 Stradella (PV), Italy

$\mathrm{Tel}+39038552214$

Fax +390385582182

Email francesca_cagnoni8I@yahoo.it
Abstract: The renin-angiotensin-aldosterone system (RAAS), an important regulator of blood pressure and mediator of hypertension-related complications, is a prime target for cardiovascular drug therapy. Angiotensin-converting enzyme inhibitors (ACEIs) were the first drugs to be used to block the RAAS. Angiotensin II receptor blockers (ARBs) have also been shown to be equally effective for treatment. Although these drugs are highly effective and are widely used in the management of hypertension, current treatment regimens with ACEIs and ARBs are unable to completely suppress the RAAS. Combinations of ACEIs and ARBs have been shown to be superior than to either agent alone for some, but certainly not all, composite cardiovascular and kidney outcomes, but dual RAAS blockade with the combination of an ACEI and an ARB is sometimes associated with an increase in the risk for adverse events, primarily hyperkalemia and worsening renal function. The recent introduction of the direct renin inhibitor, aliskiren, has made available new combination strategies to obtain a more complete blockade of the RAAS with fewer adverse events. Renin system blockade with aliskiren and another RAAS agent has been, and still is, the subject of many large-scale clinical trials and furthermore, is already available in some countries as a fixed combination.

Keywords: angiotensin II receptor blockers, renin-angiotensin-aldosterone system, hypertension, angiotensin-converting enzyme inhibitors

\section{Introduction: the blockade of the renin- angiotensin-aldosterone system}

In the last decades, renin-angiotensin-aldosterone system (RAAS) has become, unquestionably, a key point in the pathophysiology of cardiovascular and kidney diseases.

Activation of the RAAS occurs following the release of renin by the kidney. Renin is a proteinase enzyme that catalyzes cleavage of angiotensinogen to form angiotensin I (Ang I). Ang I is itself inactive but is converted to the biologically active peptide angiotensin II (Ang II) by angiotensin-converting enzyme (ACE), which is produced in the lungs and cleaves the Ang I molecule.

Ang II binds with the type 1 Ang II receptors (AT1) in the smooth muscle cells of the peripheral blood vessels causing vasoconstriction, and hence increased peripheral vascular resistance and increased blood pressure (BP; Figure 1). Ang II is recognized to be a major contributor to the progression of cardiovascular and kidney diseases. ${ }^{1-4}$

Activation of AT1 receptors by Ang II also stimulates release of the mineralocorticoid, aldosterone, from the adrenal gland, situated superior to the kidney. Aldosterone promotes sodium and water retention along the nephron, further increasing the BP. 


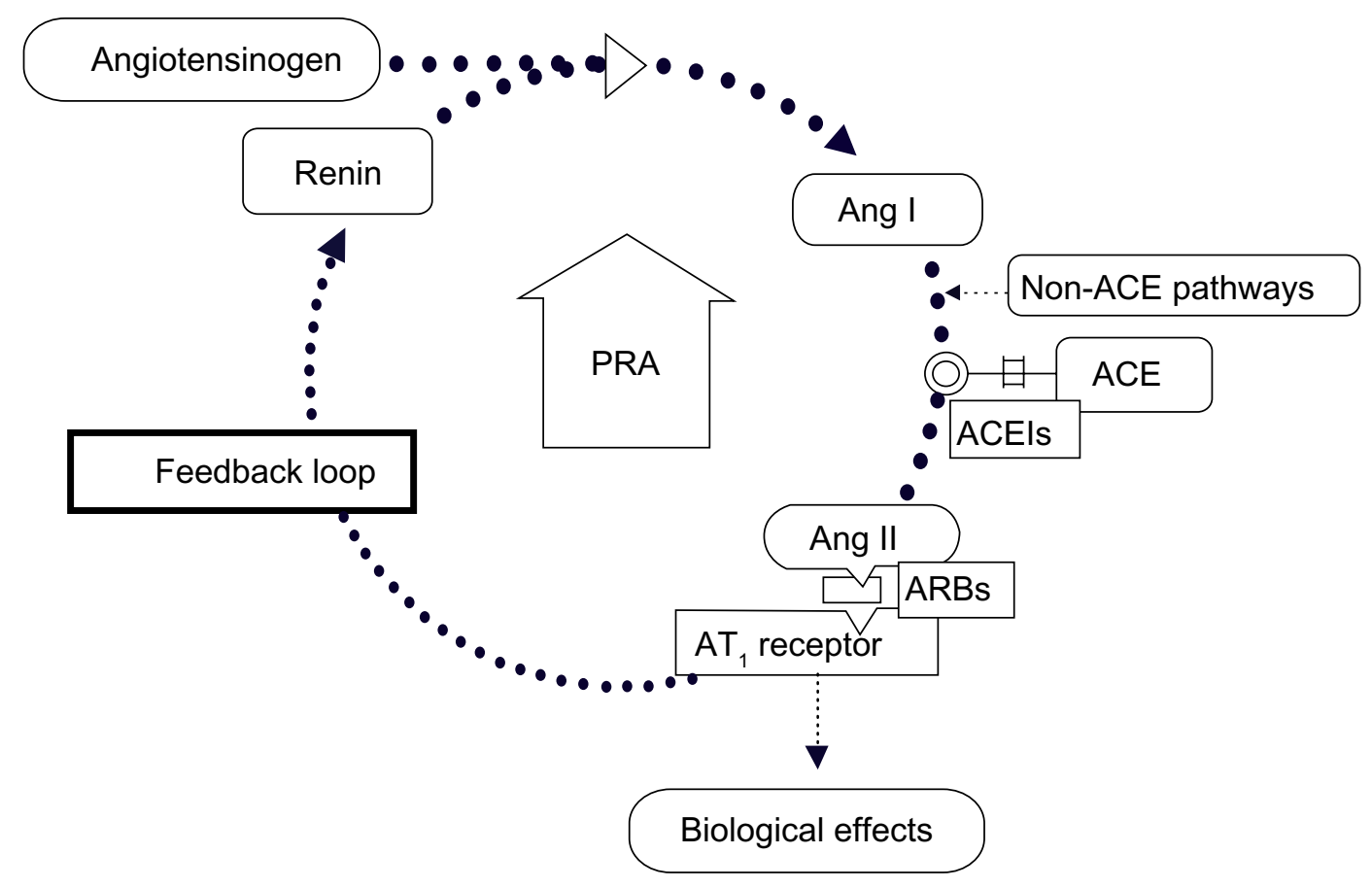

Figure I ACEls and ARBs cause compensatory increases in PRA.

Abbreviations: ACE, angiotensin-converting enzyme; ACEls, angiotensin-converting enzyme inhibitors; ARBs, angiotensin receptor blockers; PRA, plasma renin activity; Ang I, angiotensin I; Ang II, angiotensin II; ATI, type I Ang II receptor.

Plasma renin activity (PRA) is a measure of the level of activity in the RAAS, and consequently, it can be used as an indicator to detect dysregulation of the RAAS. As a matter of fact, PRA reflects the capacity of circulating renin to cleave angiotensinogen to form Ang I, and thus provides a measure of the level of activity in the RAAS.

The RAAS is targeted at different places by the existing antihypertensive therapies. Angiotensin-converting enzyme inhibitors (ACEIs) reduce the production of Ang II by inhibiting the conversion of Ang I to Ang II by these enzymes. Angiotensin receptor blockers (ARBs) antagonize AT1 receptors and prevent Ang II from binding. However, ACEIs and ARBs are associated with a feedback loop that increases PRA, as loss of stimulation of AT1 receptors on juxtaglomerular cells in the kidney (ie, removal of negative feedback) leads to a compensatory increase in renin release. The resulting increase in PRA may limit the organ protection offered by these drugs ${ }^{5}$ (Figure 1).

The whole RAAS is, therefore, upregulated although AT1 receptor-mediated effects of the effector molecule Ang II are blocked. Direct renin inhibitors (DRI) target the RAAS at its point of activation, resulting in the reduction of PRA (Figure 2).

As DRI reduces PRA, the production of Ang I decreases, resulting in less substrate availability for conversion to Ang II by ACE or other enzymes. In doing so, direct renin inhibition produces effective overall RAAS suppression. ${ }^{5}$

The functional renin receptor plays a pivotal role in Ang II production and cellular responses to renin. The binding of renin to its receptor triggers intracellular signals by rapid activation of mitogen-activated protein kinases, ie, extracellular signal-regulated protein kinases 1 and 2, and may increase plasma activator inhibitor-1 - a prothrombotic agent - levels via this mechanism. Furthermore, the bound renin has increased catalytic efficiency for the cleavage of angiotensinogen to form Ang I, facilitating Ang II production (by ACE or vascular muscle smooth chymase) at the cell surface. This may have consequences in terms of organ damage and progression of cardiovascular disease. ${ }^{6,7}$

It is now clear that the blockade of the RAAS not only reduces the $\mathrm{BP}$ but also decreases the risk of cardiovascular events and slows the progression of renal disease in different types of patients. ${ }^{8-11}$ Nevertheless, some patients do not respond adequately to the conventional renin-angiotensin system blockade, raising a clinical problem that qualifies the patient still at high risk for cardiovascular or renal diseases; in a significant number of patients, in fact, even if the target of lowering BP is obtained, the RAAS blockade with an ACE inhibitor or an ARB does not reduce the risk 


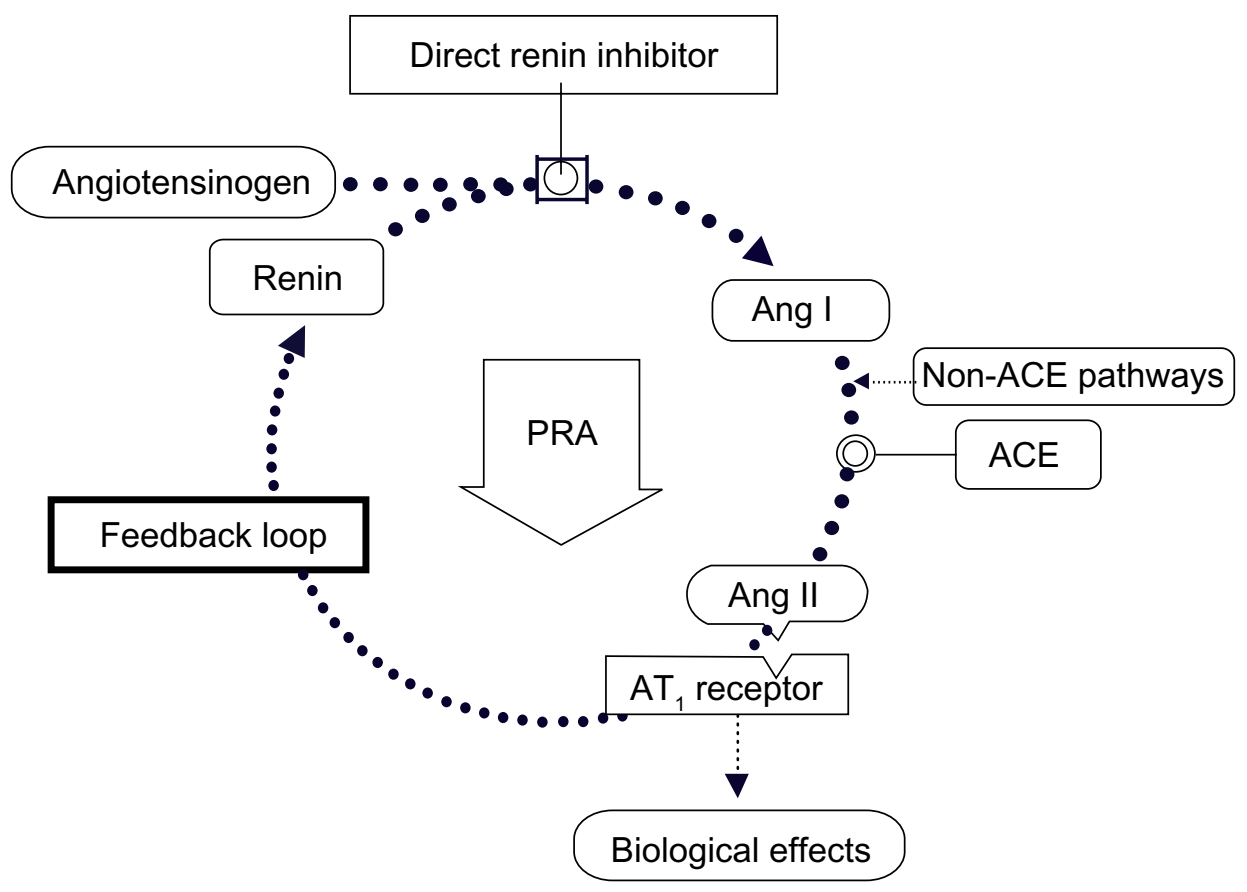

Figure 2 Direct renin inhibition acts at the point of activation of the renin system and neutralizes the PRA increase.

Abbreviations: ACE, angiotensin-converting enzyme; PRA, plasma renin activity; Ang I, angiotensin I; Ang II, angiotensin II; ATI, type I Ang II receptor.

of experiencing cardiovascular events and chronic heart and kidney disease progress despite the therapy. ${ }^{9,12-16}$ Incomplete blockade of the RAAS at recommended doses may be one explanation for this observation. ${ }^{17,18}$ Not withstanding the evolution from ACE inhibitors to ARBs, the RAAS will not be fully blocked using just these molecules alone. ${ }^{17,19,20}$ Accordingly, one strategy to improve the efficacy of RAAS blockade is to combine ACEIs and ARBs. ACEIs and ARBs combination has been widely studied in patients with hypertension, nephropathy, diabetes, myocardial infarction (MI), and heart failure. ${ }^{21}$

This review intends to examine the rationale for RAAS blockade at different levels using combinations of different molecules acting on this system; we will consider at first the characteristics of ACEI/ARBs combinations, following a pathway that will bring us to the actual use of DRIs alone or in fixed combination with ARBs.

\section{ACEI/ARB combination therapy}

Although the theoretical benefits of combined ACEIbased and ARB-based therapy may enhance BP control and improve clinical outcomes in some subpopulations of patients, in 2006, Weber and Giles ${ }^{22}$ already observed that, for the most patients, these RAAS-based therapies do not reduce the risk for major cardiovascular events to the expected extent based on the vital role of the RAAS in the pathophysiology of hypertension and cardiorenal disease They speculated that this may indicate that the RAAS is not as widely dysregulated in hypertension as previously believed, or that the current strategies and/or agents available for RAAS suppression are not as effective as they could or should be. With respect to the latter argument, dual RAAS blockade at different sites in the RAAS pathway theoretically would have provided additive protective effects by further reducing systemic and local levels of some or all angiotensin peptides, which could further inhibit formation of the Ang II. ${ }^{23-26}$ On the same topic, combinations of ACEIs and ARBs have generally been shown to produce small but significant additional reductions in BP compared with either monotherapy; ${ }^{27,28}$ although several studies have shown that ACEI/ARB combinations result in modest improvement in BP and proteinuria compared with treatment with only one of these drug classes, ${ }^{2,13,29-31}$ others do not support this combination because of concerns about efficacy (modest improvement in BP with limited or no additional benefit on outcomes) and safety. ${ }^{32}$ For instance, in a crossover study of 64 hypertensive patients not achieving BP control with full-dose valsartan, the addition of amlodipine reduced ambulatory 24-hour BP to a greater extent than the addition of benazepril $(-15.2 /-9.9 \mathrm{mmHg}$ vs $-8.6 /-6.3 \mathrm{mmHg}$, respectively). ${ }^{33}$ Similarly, ACEI/ ARB combination therapy was less effective for lowering 
BP than ARB/thiazide diuretic combination therapy in a study of 327 hypertensive patients uncontrolled by ARB monotherapy ${ }^{34}$ and in a study of 88 African Americans with hypertension. ${ }^{35}$

The Valsartan in Acute Myocardial Infarction (VALIANT) study of 14,703 elderly patients with left ventricular systolic dysfunction, congestive heart failure (CHF), or both after MI reported similar rates of all-cause mortality, death from cardiovascular events, recurrent MI, and hospitalization for heart failure for all three of its treatment groups (ACEI, ARB, and ACEI/ARB), accompanied by significantly $(P<0.05)$ more adverse events in the combination therapy group. ${ }^{36}$

Two meta-analyses of patients with CHF or left ventricular dystrophy (LVD; including CHARM-Added, Val-HeFT, and VALIANT) yet showed that ACEI/ARB combination therapy significantly increases the risk for adverse events (eg, hypertension, worsening renal function, and hyperkalemia), inducing treatment discontinuation. ${ }^{37,38}$ On the other hand, in the Randomized Evaluation of Strategies for Left Ventricular Dysfunction pilot study, ${ }^{39} \mathrm{ACEI} / \mathrm{ARB}$ combination therapy, compared with monotherapy, significantly limited the increases in end-diastolic and end-systolic volumes $(P<0.01)$ and reduced brain natriuretic peptide, a biomarker of heart failure. ${ }^{40}$ Again in the Candesartan in Heart Failure: Assessment of Reduction in Mortality and Morbidity trial ${ }^{30}$ after a median follow-up of 41 months, fewer patients taking the ACEI/ARB combination (38\%), compared with those receiving ACEI plus placebo (42\%), experienced the primary composite end point of cardiovascular death or hospitalization for chronic heart failure $(P=0.01)$.

However, some recent large trials have failed to find better cardiovascular outcomes with the ACEI/ARB combination despite better BP reductions.

The Valsartan Heart Failure Trial ${ }^{41}$ determined whether valsartan could further reduce morbidity and mortality in patients with heart failure, who already receiving optimal therapy (including ACEIs in 93\% of patients and $\beta$-blockers in $35 \%$ of patients). The primary end point of mortality was similar for the valsartan and placebo groups, whereas the combined primary end point of morbidity and mortality was significantly reduced $(P=0.009)$ in patients receiving valsartan plus optimal therapy compared with the placebo group. This benefit was primarily due to a $24 \%$ reduction in hospitalizations for heart failure in valsartan-treated patients. A subgroup analysis of patients on different background therapies revealed that valsartan had a favorable effect on the combined primary end point in those receiving an ACEI $(P=0.002)$, a $\beta$-blocker $(P=0.037)$, or no background therapy $(P=0.003)$. In contrast, in patients receiving both an ACEI and a $\beta$-blocker, valsartan had an adverse effect on mortality $(P=0.009)$, suggesting that this particular approach to comprehensive blockade of neurohormone systems in heart failure may be detrimental. ${ }^{41}$

In the Ongoing Telmisartan Alone and in Combination With Ramipril Global Endpoint Trial, ${ }^{28}$ combination therapy with telmisartan plus ramipril produced no greater reduction in the primary end point of death from cardiovascular events, MI, stroke, or hospitalization for heart failure than either component monotherapy in high-risk patients with cardiovascular disease or diabetes but without heart failure. Combination therapy was associated with an increased risk of hypotension $(P<0.001)$, syncope $(P=0.03)$, hyperkalemia $(P<0.001)$, and acute renal impairment $(P<0.001)$. The reasons for the lack of additional benefits with combination therapy, despite an additional reduction in systolic BP of $3.4 \mathrm{mmHg}$, compared with ACEI monotherapy are unknown. As the investigators pointed out, the majority of patients were also receiving statins, $\beta$-blockers, and antiplatelet medications so that additional RAAS blockade with the ACEI/ARB combination therapy resulted in little additional clinical benefit compared with the ACEI therapy alone. ${ }^{28}$

Although it is clear that monotherapy with ACE inhibitors or ARBs is effective in reducing cardiovascular mortality and morbidity in patients with heart failure, the reasons for the different cardiovascular outcomes in trials examining ACEI/ARB combinations may relate to different patient populations, previous or concurrent successful treatment with other drugs, or study design. As noted by Arici and Erdem, ${ }^{32}$ many clinical studies have been small and of short duration, and most used submaximal doses of ACEIs and ARBs both alone and in combination. Most combination studies were not designed to maximize BP control and in fact, achieved only modest improvement in BP ( 3-4 mmHg) over monotherapy with an ACEI or ARB. ${ }^{42}$ In addition, many early studies used once-daily dosing with short-acting ACEIs. Therefore, it is possible that low ACEI concentrations at trough in combination studies using shortacting ACEIs could have increased the likelihood of both acute (method related) and chronic (mechanistic mediated) ACE escape. Administration of diuretics also has resulted in increases in PRA, ${ }^{43}$ and the use of diuretics as concurrent 
medications usually is permitted in ACEI and ARB studies. Increases in both PRA and ACE escape have been associated with adverse clinical outcomes in patients on ACEI or ARB therapy. For example, in a study of 70 patients with CHF, elevated PRA despite 6 months of treatment with an ACEI was an independent predictor of elevated Ang II levels $(P=0.0004)$, and elevated plasma Ang II levels were an independent predictor of death or worsening $\mathrm{CHF}$ $(P=0.002) .{ }^{44}$ In another study, 699 patients with $\mathrm{CHF}$ underwent a complete clinical and biochemical workup at baseline and were monitored for a median of 23 months; $81 \%$ of them were receiving an ACEI or ARB. ${ }^{45}$ Elevated baseline PRA was an independent predictor of death or the need for cardioversion in patients with implantable cardioverter devices $(P<0.001)$, and PRA was higher in patients on RAAS inhibitors relative to those not receiving RAAS inhibitors $(P=0.017)$. In Val-HeFT, analysis of 4,300 patients with CHF, who had neurohormonal measurements, showed that increased baseline PRA was an independent predictor of all-cause mortality $(P=0.011)$ and of combined mortality and morbidity $(P=0.0025) .{ }^{46}$ This was observed despite the fact that the majority of patients were receiving treatment with an ACEI and approximately $50 \%$ were also receiving treatment with an ARB. A recent post hoc analysis of Val-HeFT data showed that PRA was 3.7 times higher in patients receiving ACEIs (vs those not receiving them), and that higher PRA at baseline was associated with greater mortality among patients receiving ACEIs $(P=0.0005){ }^{47}$

All together, these findings strongly indicate that PRA is related to adverse clinical outcomes even for patients receiving treatment with $\mathrm{ACEIs}$ and/or $\mathrm{ARBs}$ and further raises the possibility that DRIs may be useful alone or in combination with ACEIs or ARBs for reducing the risk for these outcomes.

\section{Direct renin inhibitor}

\section{Pharmacokinetic and pharmacodynamic}

Aliskiren, an octanamide, is the first representative of a new class of nonpeptide, low molecular weight, orally effective transition-state renin inhibitors. ${ }^{48-50}$ It is a DRI that has a high binding affinity for renin, and this may be explained by a number of interactions with the enzyme's active site. In healthy humans, aliskiren of doses between 40 and $640 \mathrm{mg}$ exerts a dose-dependent reduction in PRA, Ang I, and Ang II levels. The molecule is superior in reducing PRA compared with ARBs. Again, aliskiren at a dose of $300 \mathrm{mg}$ decreases PRA in hypertensive patients by approximately $50 \%-80 \%{ }^{51,52}$ and reduces PRA and plasma levels of Ang I and Ang II for 48 hours. ${ }^{53}$ Furthermore, urinary aldosterone was reduced at a dose of $80 \mathrm{mg}$ or more, and sodium extraction was increased to $91 \%$ at a dose of $640 \mathrm{mg} .{ }^{54}$ Compared with valsartan, aliskiren more strongly decreases the activity of renin in the circulation and reduces the excretion of urinary aldosterone for a longer period. ${ }^{53,55}$ Following oral administration, peak plasma concentrations of aliskiren are reached within 1-3 hours. ${ }^{52,53,56-58}$ The plasma half-life of aliskiren in humans shows a slow terminal elimination at 23-70 hours ${ }^{59-61}$ and approximately $47 \%-51 \%$ of aliskiren is bound by plasma proteins in humans, independent of the concentration. ${ }^{59,62,63}$ Based on in vitro studies, the major enzyme responsible for its metabolism appears to be Cytochrome P450 (CYP3A4). Aliskiren does not inhibit the CYP450 isoenzymes (CYP1A2, CYP2C8, CYP2C19, CYP2D6, CYP2E1, and CYP3A), and the main elimination route of aliskiren is via feces in its unmetabolized form. ${ }^{64}$ Approximately one-fourth of the absorbed dose also appears in the urine as unchanged compound; the pharmacokinetic and pharmacodynamic differences of aliskiren between Caucasians and Japanese are minimal and no clinically important pharmacokinetic differences were observed between patients with type 2 diabetes and normal population: the half-life of this drug was 40 hours and 44 hours in healthy subjects and patients with diabetes, respectively. ${ }^{58,61}$

\section{Clinical features}

Aliskiren is well tolerated by all age groups, including the very elderly, and there are no indications to change the recommended dose of aliskiren in patients with hepatic and renal insufficiency because the peak concentration, area under the curve (AUC), and half-life were only slightly greater in patients with hepatic dysfunction. ${ }^{52}$ Aliskiren exposure was also increased slightly in patients with renal function impairment, but these changes did not correlate with creatinine clearance. ${ }^{62}$ All agents that inhibit the RAAS activate the negative feedback loop that leads to a compensatory increase in plasma renin concentration. When this increase occurs during treatment with ACEIs and ARBs, the result is increased levels of PRA but during treatment with aliskiren, the effect of increased renin levels is blocked, so the levels of Ang I and Ang II, as well as PRA, are all reduced. ${ }^{52}$ The clinical trials do not report any major adverse effects of aliskiren compared with ARBs or 
ACEs being generally well tolerated by all patients. The most common adverse events of aliskiren are diarrhea, headache, nasopharyngitis, dizziness, fatigue, back pain, gastrointestinal disorders, rash, and renal stones. ${ }^{52,55,62,65}$ Because aliskiren directly inhibits the RAAS, theoretically adverse events such as coughing and angioedema may also occur; as a matter of fact, few cases of edema involving the face, lips, tongue, hands, and whole body have been reported to involve more than $1 \%$ of patients treated with aliskiren, which also occur at a similar or greater extent in patients receiving placebo. ${ }^{52,62,65}$ Aliskiren has the same contraindications as ACEIs and ARBs, including hypersensitivity reactions to the molecule, pregnancy, and bilateral renal-artery stenosis.

Nussberger et $\mathrm{a}^{56}$ first reported the clinical effects of aliskiren compared with enalapril and placebo. Subjects were randomized into three 8-day treatments with enalapril $20 \mathrm{mg} / \mathrm{d}$ or placebo, aliskiren 40 or $160 \mathrm{mg} / \mathrm{d}$, and aliskiren 80 or $640 \mathrm{mg} / \mathrm{d}$.

Aliskiren produced dose-dependent reductions in PRA, Ang I, and Ang II vs placebo. Inhibition of Ang II production on day 8 was superior to that of placebo with aliskiren $160 \mathrm{mg}$, aliskiren $640 \mathrm{mg}$, and enalapril. Reductions in plasma and urine aldosterone concentrations were similar between enalapril and aliskiren doses greater than $40 \mathrm{mg} / \mathrm{d}$. All subjects were normotensive upon enrollment, and no changes in BP or heart rate were observed. Adverse events were similar among all treatment groups, including enalapril and placebo. Orthostasis and dizziness following blood draws were reported in all treatment groups, with a tendency toward increased dizziness with aliskiren $640 \mathrm{mg}$ (actual incidence not reported).

Stanton and colleagues ${ }^{66}$ performed a randomized, double-blind, parallel-group study in 226 patients aged 21-70 years with mild to moderate essential hypertension comparing the 4-week BP-lowering effects and safety of aliskiren $37.5,75,150$, and $300 \mathrm{mg} / \mathrm{d}$ with those of losartan $100 \mathrm{mg} / \mathrm{d}$ and showed dose-dependent decreases in daytime ambulatory systolic BP and PRA in patients treated with aliskiren. There was no difference in BP lowering of daytime ambulatory systolic BP between aliskiren 75, 150, and $300 \mathrm{mg} / \mathrm{d}$ and losartan $100 \mathrm{mg} / \mathrm{d}$. The BP-lowering activity of the $300 \mathrm{mg}$ dose persisted for 24 hours. With aliskiren, PRA fell dose-dependently by $50 \%-80 \%$, whereas it doubled with losartan. The authors concluded that aliskiren, through inhibition of renin, was an effective and safe orally active BP-lowering drug. ${ }^{66}$

In a double-blind, randomized parallel-group trial, Gradman and colleagues ${ }^{67}$ assigned 652 hypertensive patients once-daily doses of $150 \mathrm{mg}, 300 \mathrm{mg}$, or $600 \mathrm{mg}$ aliskiren, $150 \mathrm{mg}$ irbesartan, or placebo. The reductions in BP (systolic/ diastolic) measured at trough after 8 weeks of follow-up and adjusted for baseline values and the difference from placebo averaged $6.1 / .9,1.5 / .4,1.4 / .2$, and $7.2 / 2.5 \mathrm{mmHg}$ on the increasing doses of aliskiren and irbesartan, respectively. The 2 highest aliskiren doses lowered diastolic BP significantly more than irbesartan $(P=0.01)$. The frequency of adverse effects was similar for placebo and aliskiren with the exception of diarrhea associated with the dose $600 \mathrm{mg} / \mathrm{d}(1.5 \%$ vs $6.9 \%)$.

\section{Dual blockade DRI/ARB}

Because aliskiren is more likely, at least initially, to be added into existing therapy than to be used for newly diagnosed patients, much of the phase 3 clinical studies have investigated its use as add-on therapy to the major classes. Indeed, aliskiren has been studied both in comparison to and in combination with each of the RAAS-blocking drugs, ACEIs, and ARBs.

An early study in healthy human volunteers explored the effect of aliskiren in combination with an ARB on components of the RAAS, comparing the effects of aliskiren, valsartan, and their combination on PRA, Ang II, and aldosterone. ${ }^{53}$ A single dose of $300 \mathrm{mg}$ aliskiren inhibited PRA by $95.6 \%$ compared with baseline at 4 hours, and it remained below placebo for 48 hours $(P<0.05)$. Similarly, Ang II decreased and remained below placebo for 48 hours $(P<0.05)$. In contrast, $160 \mathrm{mg}$ valsartan increased PRA and Ang II levels within 4 and 6 hours of dosing, respectively, and they were still higher than placebo at 24 and 48 hours $(P<0.05)$. The combination of $150 \mathrm{mg}$ aliskiren and $80 \mathrm{mg}$ valsartan decreased PRA below placebo values at 4 hours $(P<0.05)$, with a subsequent return to baseline by 12 hours. All the three treatments significantly $(P<0.05)$ decreased plasma levels and urinary excretion of aldosterone for at least 4 hours after dosing compared with placebo. Aliskiren alone or in combination with valsartan reduced 24-hour cumulative urinary aldosterone excretion to a greater extent $(P<0.05)$ than did valsartan alone. Overall, in this study, the low-dose combination of aliskiren and valsartan produced enhanced blockade of the components of the RAAS that were equal to those produced by the higher dose of aliskiren and higher to those produced by the standard dose of valsartan.

The safety and tolerability of dual RAAS blockade with aliskiren for treatment of heart failure was examined in the Aliskiren Observation of Heart Failure Treatment study 
(ALOFT) ${ }^{68}$ In this study, patients $(\mathrm{n}=302)$ were randomized to receive aliskiren ( $150 \mathrm{mg}$ daily) or placebo for 3 months in addition to standard therapy. A $98 \%$ of the placebo group and $99 \%$ of the aliskiren group were also receiving an ACEI or an ARB. In patients receiving aliskiren, the incidences of renal dysfunction, hypotension, and hyperkalemia were similar to placebo. In this study, $N$-terminal prohormone brain natriuretic peptide, an important biomarker of heart failure prognosis and the primary efficacy outcome measure, increased with placebo but decreased with aliskiren $(P=0.01)$. Serum levels of the related biomarker brain natriuretic peptide decreased with both placebo and aliskiren, ie, to a significantly greater extent with aliskiren than with placebo $(P=0.02)$. Aliskiren also caused a greater reduction in PRA $(P<0.0001)$ and 24-hour urinary aldosterone excretion $(P=0.02)$ compared with placebo (Table 1$)$.

In the Aliskiren Left Ventricular Assessment of Hypertrophy (ALLAY) study, in which patients with hypertension and left-ventricular hypertrophy $(\mathrm{LVH})$ were randomized to aliskiren (300 mg), losartan (100 mg), or their combination, aliskiren was noninferior to losartan in reducing LV mass index, even if the combination was not superior to losartan alone. ${ }^{71}$ These findings suggest that aliskiren is an effective and well-tolerated treatment option for patients with $\mathrm{LVH}$. The lack of additional benefit with combination therapy may be related to the design of the study in which there was no significant difference in BP reduction between groups. LV mass reduction seems to be directly related to BP reduction. Tolerability and safety were similar in all treatment groups.

In some recent important trials, aliskiren has also shown renoprotective potential in patients with type 2 diabetes and albuminuria, ${ }^{70,72}$ the best available surrogate parameter in the treatment of diabetic nephropathy, associated with risk of renal and cardiovascular events. ${ }^{15,73}$

In the Aliskiren in the Evaluation of Proteinuria in Diabetes (AVOID) trial, Parving et al ${ }^{70}$ evaluated the effects of dual blockade of the RAAS with aliskiren and losartan in patients $(n=599)$ with hypertension and type 2 diabetes with nephropathy. Patients were maintained on losartan (100 mg daily) for the duration of the study and were randomized to receive a 6 -month treatment with aliskiren $(150 \mathrm{mg} / \mathrm{d}$ for 3 months, then $300 \mathrm{mg} / \mathrm{d}$ for 3 months) or placebo. After 3 months of treatment with aliskiren $(150 \mathrm{mg} / \mathrm{d})$, the urinary albumin/creatinine ratio (UACR) had decreased by $11 \%$ compared with placebo $(P=0.02)$. Increasing the dose of aliskiren to $300 \mathrm{mg} / \mathrm{d}$ caused a further decrease in the UACR to $20 \%(P<0.001)$. A nonsignificant difference in $\mathrm{BP}$ was seen between the treatment groups, suggesting that the renoprotective effect of aliskiren was independent of

Table I Aliskiren and ACEls or ARBs combination therapy

\begin{tabular}{|c|c|c|c|c|c|}
\hline Patients & $\mathbf{N}$ & Duration & Treatment (mg/d) & Results & References \\
\hline \multicolumn{6}{|l|}{ Hypertension } \\
\hline $\begin{array}{l}\text { Hypertension with } \\
\text { diabetes }\end{array}$ & 837 & $8 w k$ & $\begin{array}{l}\text { Aliskiren (300) } \\
\text { Ramipril (I0) } \\
\text { Aliskiren/ramipril (300/10) }\end{array}$ & $-14.7 /-11.3^{\mathrm{a}}$ & Uresin et $\mathrm{al}^{69}$ \\
\hline $\begin{array}{l}\text { Mild-to-moderate } \\
\text { hypertension }\end{array}$ & $\mathrm{I}, 797$ & 8 wk & $\begin{array}{l}\text { Aliskiren }(300) \\
\text { Valsartan (320) } \\
\text { Aliskiren/valsartan (300/320) }\end{array}$ & $\begin{array}{l}-13.0 /-9.0 \\
-12.8 /-9.7 \\
-17.2 /-12.2\end{array}$ & Oparil et al ${ }^{55}$ \\
\hline \multicolumn{6}{|l|}{ Chronic kidney disease } \\
\hline $\begin{array}{l}\text { Type } 2 \text { diabetes with } \\
\text { nephropathy }\end{array}$ & 524 & $6 \mathrm{mo}$ & $\begin{array}{l}\text { Losartan (100) } \\
\text { Aliskiren (300) } \\
\text { Losartan/aliskiren (100/300) }\end{array}$ & $\begin{array}{l}\text { Aliskiren/losartan reduced } \\
\text { UACR by } 20 \% \text { compared } \\
\text { with losartan alone }\end{array}$ & $\begin{array}{l}\text { Parving et } \text { al }^{70} \\
\text { The AVOID Study }\end{array}$ \\
\hline \multicolumn{6}{|l|}{ Heart failure } \\
\hline $\begin{array}{l}\text { NYHA class II-IV } \\
\text { heart failure }\end{array}$ & 302 & $3 \mathrm{mo}$ & $\begin{array}{l}\text { Aliskiren (I50) or placebo } \\
\text { (plus standard therapy } \\
\text { including ACEls and ARBs) }\end{array}$ & $\begin{array}{l}\text { Aliskiren decreased plasma } \\
\text { NT-proBNP and BNP }\end{array}$ & $\begin{array}{l}\text { McMurray et al }{ }^{68} \\
\text { The ALOFT Study }\end{array}$ \\
\hline $\begin{array}{l}\text { Left-ventricular } \\
\text { hypertrophy }\end{array}$ & & & & & \\
\hline $\begin{array}{l}\text { Hypertension with } \\
\text { increased left-ventricular } \\
\text { wall thickness }\end{array}$ & 465 & $9 \mathrm{mo}$ & $\begin{array}{l}\text { Losartan (100) } \\
\text { Aliskiren (300) } \\
\text { Losartan/Aliskiren (100/300) }\end{array}$ & $\begin{array}{l}\text { Left-ventricular mass } \\
\text { reduced to a similar extent } \\
\text { in all treatment groups }\end{array}$ & $\begin{array}{l}\text { Solomon et al }{ }^{71} \\
\text { The ALLAY Study }\end{array}$ \\
\hline
\end{tabular}

${ }^{\mathrm{a}}$ Change in mean sitting systolic/mean sitting diastolic blood pressure $(\mathrm{mmHg})$.

Abbreviations: ACEls, angiotensin-converting enzyme inhibitors; ARBs, angiotensin receptor blockers; UACR, urinary albumin/creatinine ratio; NYHA, New York Heart Association; NT, N-terminal; BNP, brain natriuretic peptide. 
BP. There was no difference in the rates of adverse events, such as hyperkalemia, or discontinuation rates between the 2 groups.

In a subsequent double-blind, randomized, crossover study, 26 patients with type 2 diabetes, hypertension, and albuminuria ( $>100 \mathrm{mg} / \mathrm{d})$ were randomly assigned to four 2-month treatment periods in random order with placebo, $300 \mathrm{mg}$ aliskiren once daily, $300 \mathrm{mg}$ irbesartan once daily, or the combination of two drugs with identical doses. Persson and colleagues ${ }^{74}$ yet demonstrated that with the combination of $300 \mathrm{mg}$ aliskiren and $300 \mathrm{mg}$ irbesartan, the reduction in albuminuria was enhanced compared with the reduction obtained with the 2 monotherapies. The added antiproteinuric effect with combination treatment compared with aliskiren alone was $31 \%$.

All these studies suggest that aliskiren plus an ARB may provide cardiorenal benefits that go beyond those solely attributable to lowering of BP. The DRI approach to RAAS suppression is still very recent and the ultimate role of aliskiren in combination therapies with ACEIs, ARBs, and other antihypertensives will be better defined through future studies, which are being conducted as part of the ASPIRE HIGHER clinical program. ${ }^{75,76}$

On the other hand, the dual blockade in post-MI seems not be as useful as in the previous reported conditions. As a matter of fact, the results of the recently presented study ASPIRE $^{77}$ (designed to test the hypothesis that aliskiren on top of standard therapy would improve remodeling in post-MI patients with LV dysfunction) have shown the following:

- The primary end point (LVESV) was nonsignificant; however, consistent trends toward smaller ventricles were seen in the aliskiren group and early post hoc analyses suggest a potential benefit in post-MI patients with diabetes.

- Secondary composite end points were not different, with no statistical difference in any of the components.

- There was a nonsignificant trend toward higher mortality in the aliskiren group, although total mortality (3\%) is low compared with the other post-MI trials.

- Hyperkalemia, hypotension, and renal dysfunction were increased in the aliskiren group overall.

Summarizing, based on echocardiographic markers, the ASPIRE study does not support the addition of aliskiren to an ACEI or an ARB in post-MI patients with impaired left ventricular function. Although early post hoc analyses may point toward a beneficial effect in favor of aliskiren in some subgroups (eg, patients with diabetes), ASPIRE as a hypothesis-generating trial does not support a morbidity and mortality study in post-MI patients.

\section{Conclusion}

Even though awareness and treatment of hypertension have increased over the years, substantial improvements in BP control rates are still lacking, with approximately two-thirds of hypertensive adults aged 35-64 years failing to reach a BP target of $<140 / 90 \mathrm{mmHg}$. Nowadays, it is well known that the majority of hypertensive patients require 2 or more agents to reach BP goal. Not only epidemiological or observational researches but also important and wide clinical trials, including Antihypertensive and Lipid-Lowering Treatment to Prevent Heart Attack Trial (ALLHAT), Avoiding Cardiovascular Events through Combination Therapy in Patients Living with Systolic Hypertension (ACCOMPLISH), The International Verapamil SR/Trandolapril Study (INVEST), and The Losartan Intervention For Endpoint reduction (LIFE), have reported that $23 \%-54 \%$ patients require 3 or more antihypertensive agents for BP control and target-level maintenance $(<140 / 90$ or $<130 / 80 \mathrm{mmHg}$ depending on cardiovascular risk). ${ }^{78-81}$ In patients with $\mathrm{BP} \geq 20 / 10 \mathrm{mmHg}$ above goal, on average, 3.2 drugs might be needed to achieve BP control. ${ }^{82}$

The problem of the comorbidity and its consequence the coadministration of multiple drugs - may be substantial for elderly patients. In a recent trial conducted by Yarrows and colleagues, ${ }^{83,84}$ the aliskiren/valsartan combination therapy had been studied in elderly patients too compared with those younger than 65 years of age. The combination provided significantly greater reductions in SBP systolic BP and BP control rates than did valsartan monotherapy in the elderly patients, and the effect of aliskiren/valsartan and high-dose valsartan on pulse pressure was greater in elderly patients than in younger patients. Aliskiren monotherapy and aliskiren/valsartan combinations were equally well tolerated in the elderly as in younger patients.

Following the above-reported data and several clinical observations, in 2009, the US Food and Drug Administration approved the fixed combination of aliskiren/valsartan at the dosages of 150/160 mg and 300/320 mg for the treatment of hypertension in patients not adequately controlled on aliskiren or ARB monotherapy and as initial therapy in patients likely to need multiple drugs to achieve their BP goals.

\section{Disclosure}

Dr Destro has received consulting and lecture fees from Novartis Pharma, Dr Destro has received Boehringer 
Ingelheim, AstraZeneca, Servier, Menarini IFR, ScheringPlough, Guidotti, Pfizer, Knoll, Bayer, Chiesi, Sankyo, Merck Sharp and Dohme, Malesci and Errekappa; he has received research support as a study investigator from Novartis Pharma, Boehringer Ingelheim, Menarini IFR, Guidotti, Bayer and Chiesi. Dr Preti received consulting and lecture fees and research support as study investigator from Novartis Pharma. Dr Cagnoni and Dr Rossi Ricci received research support as study coinvestigators from Novartis Pharma. No other potential conflict of interest relevant to this article was reported.

\section{References}

1. Russo D, Minutolo R, Pisani A, et al. Coadministration of losartan and enalapril exerts additive antiproteinuric effect in IgA nephropathy. $\mathrm{Am}$ J Kidney Dis. 2001;38(1):18-25.

2. Nakao N, Yoshimura A, Morita H, Takada M, Kayano T, Ideura T. Combination treatment of angiotensin-II receptor blocker and angiotensin-converting-enzyme inhibitor in non-diabetic renal disease (COOPERATE): a randomised controlled trial. Lancet. 2003;361(9352): 117-124.

3. Okubo S, Niimura F, Nishimura H, et al. Angiotensin-independent mechanism for aldosterone synthesis during chronic extracellular fluid volume depletion. J Clin Invest. 1997;99:855-860.

4. Epstein M. Aldosterone as a mediator of progressive renal disease: pathogenetic and clinical implications. Am J Kidney Dis. 2001; 37(4):677-688.

5. Müller D, Luft F. Direct renin inhibition with aliskiren in hypertension and target organ damage. Clin J Am Soc Nephrol. 2006;1(2): 221-228.

6. Nguyen G, Delarue F, Burckle C, et al. Pivotal role of the renin/prorenin receptor in angiotensin II production and cellular responses to renin. J Clin Invest. 2002;109(11):1417-1427.

7. Guo C, Ju H, Leung D, Massaeli H, Shi M, Rabinovitch M. A novel vascular smooth muscle chymase is upregulated in hypertensive rats. J Clin Invest. 2001;107(6):703-715.

8. Yusuf S, Sleight P, Pogue J, Bosch J, Davies R, Dagenais G. Effects of an angiotensin-converting-enzyme inhibitor, ramipril, on cardiovascular events in high-risk patients. The Heart Outcomes Prevention Evaluation Study Investigators. $N$ Engl J Med. 2000;342(3): 145-153.

9. Lewis EJ, Hunsicker LG, Bain RP, Rohde RD. The effect of angiotensin-converting-enzyme inhibition on diabetic nephropathy. The Collaborative Study Group. N Engl J Med. 1993;329(20): 1456-1462.

10. Heart Outcomes Prevention Evaluation Study Investigators. Effects of ramipril on cardiovascular and microvascular outcomes in people with diabets mellitus: results of the HOPE study and MICRO-HOPE substudy. Lancet. 2000;355(9200):253-259.

11. Parving H, Lehnert H, Rochner-Mortensen J, et al. The effect of irbesartan on the development of diabetic nephropathy in patients with type 2 diabetes. N Engl J Med. 2001;345(12):870-878.

12. Brenner BM, Cooper ME, de Zeeuw D, et al. Effects of losartan on renal and cardiovascular outcomes in patients with type 2 diabetes and nephropathy. N Engl J Med. 2001;345(12):861-869.

13. Kunz R, Friedrich C, Wolbers M, Mann J. Meta-analysis: effect of monotherapy and combination therapy with inhibitors of the renin angiotensin system on proteinuria in renal disease. Ann Intern Med. 2008;148(1):30-48.

14. Jafar TH, Schmid CH, Landa M, et al. Angiotensin-converting enzyme inhibitors and progression of nondiabetic renal disease. A meta-analysis of patient-level data. Ann Intern Med. 2001;135(2):73-87.
15. Lewis EJ, Hunsicker LG, Clarke WR, et al. Renoprotective effect of the angiotensin-receptor antagonist irbesartan in patients with nephropathy due to type 2 diabetes. N Engl J Med. 2001;345(12): 851-860.

16. Toto RD. Lessons from the African-American Study of kidney disease and hypertension: an update. Curr Hypertens Rep. 2006;8(5): 409-412.

17. Jorde UP, Ennezat PV, Lisker J, et al. E. Maximally recommended doses of angiotensin-converting enzyme (ACE) inhibitors do not completely prevent ACE-mediated formation of angiotensin II in chronic heart failure. Circulation. 2000;101(8):844-846.

18. Forclaz A, Maillard M, Nussberger J, Brunner HR, Burnier M. Angiotensin II receptor blockade: is there truly a benefit of adding an ACE inhibitor? Hypertension. 2003;41(1):31-36.

19. Maillard MP, Wurzner G, Nussberger J, Centeno C, Burnier M, Brunner HR. Comparative angiotensin II receptor blockade in healthy volunteers: the importance of dosing. Clin Pharmacol Ther. 2002;71(1): $68-76$.

20. Juillerat L, Nussberger J, Menard J, et al. Determinants of angiotensin II generation during converting enzyme inhibition. Hypertension. 1990; 16(5):564-572.

21. Ravandi A, Teo KK. Blocking the renin-angiotensin system: dual- versus mono-therapy. Expert Rev Cardiovasc Ther. 2009;7(6):667-674.

22. Weber M, Giles T. Inhibiting the renin-angiotensin system to prevent cardiovascular diseases: do we need a more comprehensive strategy? Rev Cardiovasc Med. 2006;7(7):45-54.

23. van de Wal RM, van Veldhuisen DJ, van Gilst WH, Voors AA. Addition of an angiotensin receptor blocker to full-dose ACEinhibition: controversial or common sense? Eur Heart J. 2005;26(22): 2361-2367.

24. Wolf G, Ritz E. Combination therapy with ACE inhibitors and angiotensin II receptor blockers to halt progression of chronic renal disease: pathophysiology and indications. Kidney Int. 2005;67(3): 799-812.

25. Unger T, Stoppelhaar M. Rationale for double renin-angiotensinaldosterone system blockade. Am J Cardiol. 2007;100(3A): 25J-31J.

26. Cohn J, Goldman J. Establishing a new option for target-organ protection: rationale for ARB plus ACE inhibitor combination therapy. Am J Hypertens. 2008;21(3):248-256.

27. Pfeffer M, McMurray J, Velazquez E, et al. Valsartan, captopril, or both in myocardial infarction complicated by heart failure, left ventricular dysfunction, or both. $N$ Engl J Med. 2003;349(20): 1893-1906.

28. Yusuf S, Teo KK, Pogue J, et al. Telmisartan, ramipril, or both in patients at high risk for vascular events. $N$ Engl J Med. 2008;358(15): 1547-1559.

29. Ferrari P, Marti H, Pfister M, Frey F. Additive antiproteinuric effect of combined ACE inhibition and angiotensin II receptor blockade. J Hypertens. 2002;20(1):125-130.

30. McMurray JJ, Ostergren J, Swedberg K, et al. Effects of candesartan in patients with chronic heart failure and reduced left-ventricular systolic function taking angiotensin-converting-enzyme inhibitors: the CHARM-Added trial. Lancet. 2003;362(9386):767-771.

31. Krum H, Carson P, Farsang C, et al. Effect of valsartan added to background ACE inhibitor therapy in patients with heart failure: results from Val-HeFT. Eur J Heart Fail. 2004;6(7):937-945.

32. Arici M, Erdem Y. Dual blockade of the renin-angiotensin system for cardiorenal protection: an update. Am J Kidney Dis. 2009;53(2): 332-345.

33. Stergiou GS, Makris T, Papavasiliou M, Efstathiou S, Manolis A. Comparison of antihypertensive effects of an angiotensin-converting enzyme inhibitor, a calcium antagonist and a diuretic in patients with hypertension not controlled by angiotensin receptor blocker monotherapy. J Hypertens. 2005;23(4):883-889.

34. Waeber B, Aschwanden R, Sadecky L, Ferber P. Combination of hydrochlorothiazide or benazepril with valsartan in hypertensive patients unresponsive to valsartan alone. J Hypertens. 2001;19(11): 2097-2104. 
35. Weir MR, Smith DH, Neutel JM, Bedigian MP. Valsartan alone or with a diuretic or ACE inhibitor as treatment for African American hypertensives: relation to salt intake. Am J Hypertens. 2001;14(7 Pt 1): 665-671.

36. White HD, Aylward PE, Huang Z, et al. Mortality and morbidity remain high despite captopril and/or valsartan therapy in elderly patients with left ventricular systolic dysfunction, heart failure, or both after acute myocardial infarction: results from the Valsartan in Acute Myocardial Infarction Trial (VALIANT). Circulation. 2005;112(22): 3391-3399.

37. Phillips C, Kashani A, Ko D, Francis G, Krumholz H. Adverse effects of combination angiotensin II receptor blockers plus angiotensinconverting enzyme inhibitors for left ventricular dysfunction: a quantitative review of data from randomized clinical trials. Arch Intern Med. 2007;167(18):1930-1936.

38. Lakhdar R, Al-Mallah M, Lanfear D. Safety and tolerability of angiotensin-convertingvenzyme inhibitor versus the combination of angiotensin-converting enzyme inhibitor and angiotensin receptor blocker in patients with left ventricular dysfunction: a systematic review and meta-analysis of randomized controlled trials. J Card Fail. 2008; 14(3):181-188.

39. McKelvie RS, Yusuf S, Pericak D, et al. Comparison of candesartan, enalapril, and their combination in congestive heart failure: randomized evaluation of strategies for left ventricular dysfunction (RESOLVD) pilot study. The RESOLVD Pilot Study Investigators. Circulation. 1999;100(10):1056-1064.

40. Latini R, Masson S, Wong M, et al. Incremental prognostic value of changes in B-type natriuretic peptide in heart failure. Am J Med. 2006;119(1):70.e23-70.e30.

41. Cohn J, Tognoni G. Valsartan Heart Failure Trial Investigators. A randomized trial of the angiotensin-receptor blocker valsartan in chronic heart failure. N Engl J Med. 2001;345(23):1667-1675.

42. Doulton T, He F, MacGregor G. Systematic review of combined angiotensin-converting enzyme inhibition and angiotensin receptor blockade in hypertension. Hypertension. 2005;45(5):880-886.

43. Lijnen P, Fagard R, Staessen J, Amery A. Effect of chronic diuretic treatment on the plasma renin-angiotensin-aldosterone system in essential hypertension. Br J Clin Pharmacol. 1981;12(3):387-392.

44. Roig E, Perez-Villa F, Morales M, et al. Clinical implications of increased plasma angiotensin II despite ACE inhibitor therapy in patients with congestive heart failure. Eur Heart J. 2000;21(1):53-57.

45. Vergaro G, Fontana M, Poletti R, et al. Plasma renin activity is an independent prognostic factor in chronic heart failure [abstract]. Eur Heart J. 2008;29(1):2493.

46. Latini R, Masson S, Anand I, et al. The comparative prognostic value of plasma neurohormones at baseline in patients with heart failure enrolled in Val-HeFT. Eur Heart J. 2004;25(4):292-299.

47. Masson S, Solomon S, Angelici L, et al. Plasma renin activity retains a strong prognostic value in patients with chronic HF, independent of ACE inhibitor or beta-blocker therapy. Data from the Valsartan Heart Failure (Val-HeFT) trial. Paper presented at: 31st Annual Congress of the European Society of Cardiology; 2009; Barcelona, Spain.

48. Rahuel J, Rasetti V, Maibaum J, et al. Structure-based drug design: the discovery of novel non peptide orally active inhibitors of human renin. Chem Biol. 2000;7:493-504.

49. Stanton A. Potential of renin inhibition in cardiovascular disease. J Renin Angiotensin Aldosterone Syst. 2003;4:6-10.

50. Wood JM, Cumin F, Maibaum J. Pharmacology of renin inhibitors and their application to the treatment of hypertension. Pharmacol Ther. 1994;61:325-344.

51. Bruckner A. Aliskiren (Tekturna ${ }^{\circledR}$ ) Novartis. Drug Monograph. Creighton University Drug Information Center. East Hanover, NJ: Novartis Pharmaceuticals Corporation; 2007.

52. Tecturna (aliskiren) tablets [prescribing information]. East Hanover, NJ: Novartis Phamaceuticals Corporation; 2007. Available from: http:// www.pharma.us.novartis.com/product/pi/pdf/tekturna.pdf. Accessed Apr 16, 2007.
53. Azizi M, Menard J, Bissery A, et al. Pharmacologic demonstration of the synergistic effects of a combination of the renin inhibitor aliskiren and the AT1 receptor antagonist valsartan on the angiotensin II -renin feedback interruption. J Am Soc Nephrol. 2004;15(12):3126-3133.

54. Campbell DJ. Interpretation of plasma renin concentration in patients receiving aliskiren therapy. Hypertension. 2008;51(1):15-18.

55. Oparil S, Yarows SA, Patel S, Fang H, Zhang J, Satlin A. Efficacy and safety of combined use of aliskiren and valsartan in patients with hypertension: a randomised, double-blind trial. Lancet. 2007;370(9583): 221-229.

56. Nussberger J, Wuerzner G, Jensen C, et al. Angiotensin II suppression in humans by the orally active renin inhibitor aliskiren (SPP100): comparison with enalapril. Hypertension. 2002;39(1):E1-E8.

57. Vaidyanathan S, Jermany J, Yeh CH, Bizot MN, Camisasca R. Aliskiren, a novel orally effective renin inhibitor, exhibits similar pharmacokinetics and pharmacodynamics in Japanese and Caucasin subjects. Br J Clin Pharmacol. 2006;62(6):690-698.

58. Vaidyanathan S, Limoges D, Yeh C, Dieterich H-A. Aliskiren, an orally effective renin inhibitor, shows dose linear pharmacokinetics in healthly volunteers. Clin Pharmacol Ther. 2006;79 Suppl:P64.

59. Waldmeier F, Glaenzel U, Wirtz B, et al. Absorption, distribution, metabolism and elimination of direct renin inhibitor aliskiren in healthy volunteers. Drug Metab Dispos. 2007;35(8):1418-1428.

60. Wuerzner G, Azizi M. Renin inhibition with aliskiren. Clin Exp Pharmacol Physiol. 2008;35(4):426-430.

61. Zhao C, Vaidyanathan S, Yeh CM, Maboudian M, Armin Dieterich H. Aliskiren exhibits similar pharmacokinetics in healthy volunteers and patients with type 2 diabetes mellitus. Clin Pharmacokinet. 2006;45: 1125-1134.

62. Cada DJ, Levien T, Baker DE. Aliskiren. Hosp Pharm. 2007;42: 737-749.

63. Vaidyanathan S, Valencia J, Kemp C, et al. Lack of pharmacokinetic interaction of aliskiren, a novel direct renin inhibitor for the treatment of hypertension, with the antihypertensive amlopine, valsartan, hydrochlorothiazide (HCTZ) and ramipril in healthly volunteers. Int J Clin Pract. 2006;60(11):1343-1356.

64. Staessen JA, Yah L, Richart. Oral renin inhibitor. Lancet. 2006;368(9545): 1449-1456.

65. Cheng JW. Aliskiren: renin inhibitor for hypertension management. Clin Ther. 2008;30(1):31-47.

66. Stanton A, Jensen C, Nussberger J, O'Brien E. Blood pressure lowering in essential hypertension with an oral renin inhibitor, aliskiren. Hypertension. 2003;42(6): 1137-1143.

67. Gradman A, Schmieder R, Lins R, Nussberger J, Chiang Y, Bedigian MP. Aliskiren, a novel orally effective renin inhibitor, provides dose-dependent antihypertensive efficacy and placebo-like tolerability in hypertensive patients. Circulation. 2005;111(8):1012-1018.

68. McMurray JJ, Pitt B, Latini R, et al. Effect of the oral direct renin inhibitor aliskiren in patients with symptomatic heart failure. Circ Heart Fail. 2008;1(1):17-24.

69. Uresin AY, Taylor AA, Kilo C, et al. Efficacy and safety of the direct renin inhibitor aliskiren and ramipril alone or in combination in patients with diabetes and hypertension. J Renin Angiotensin Aldosterone Syst. 2007;8:190-198.

70. Parving HH, Persson F, Lewis JB, Lewis EJ, Hollenberg NK. Aliskiren combined with losartan in type 2 diabetes and nephropathy. $N$ Engl $J$ Med. 2008;358(23):2433-2446.

71. Solomon SD, Appelbaum E, Manning WJ, et al. Effect of the direct renin inhibitor aliskiren, the angiotensin receptor blocker losartan, or both on left ventricular mass in patients with hypertension and left ventricular hypertrophy. Circulation. 2009;119(4):530-537.

72. Persson F, Rossing P, Schjoedt K, et al. Time course of the antiproteinuric and antihypertensive effects of direct renin inhibition in type 2 diabetes. Kidney Int. 2008;73:1419-1425.

73. Rossing P, Hommel E, Smidt U, et al. Reduction in albuminuria predicts a beneficial effect on progression in diabetic nephropathy during antihypertensive treatment. Diabetologia. 1994;37:511-516.

74. Persson F, Rossing P, Reinhard H, et al. Renal effects of aliskiren compared to and in combination with irbesartan in patients with type 2 diabetes, hypertension and albuminuria. Diabetes Care. 2009 Oct;32(10):1873-1879. Epub 2009 Jul 8. 
75. Parving HH, Brenner BM, McMurray JJ, et al. Aliskiren Trial in Type 2 Diabetes Using Cardio-Renal Endpoints (ALTITUDE): rationale and study design. Nephrol Dial Transplant. 2009;24(5):1663-1671.

76. Egan BM, Basile JN, Rehman SU, et al. Plasma renin test-guided drug treatment algorithm for correcting patients with treated but uncontrolled hypertension: a randomized controlled trial. Am J Hypertens. 2009; 22:792-801.

77. Solomon S. Effect of the direct renin inhibitor aliskiren on left ventricular remodeling following myocardial infarction with left ventricular dysfunction (ASPIRE). Paper presented at: American College of Cardiology 59th Annual Scientific Session; 2010; Atlanta, Georgia, USA.

78. Jamerson K, Weber MA, Bakris GL, et al. Benazepril plus amlodipine or hydrochlorothiazide for hypertension in high-risk patients. $N \mathrm{Engl}$ J Med. 2008;359(23):2417-2428.

79. Devereux RB, de Faire U, Fyhrquist F, et al. Blood pressure reduction and antihypertensive medication use in the losartan intervention for endpoint reduction in hypertension (LIFE) study in patients with hypertension and left ventricular hypertrophy. Curr Med Res Opin. 2007;23(2):259-270.
80. Bangalore S, Messerli FH, Cohen JD, et al. Verapamil-sustained release-based treatment strategy is equivalent to atenolol-based treatment strategy at reducing cardiovascular events in patients with prior myocardial infarction: an INternational VErapamil SR-Trandolapril (INVEST) substudy. Am Heart J. 2008;156(2):241-247.

81. Cushman WC, Ford CE, Cutler JA, et al. Success and predictors of blood pressure control in diverse North American settings: the antihypertensive and lipid-lowering treatment to prevent heart attack trial (ALLHAT). $J$ Clin Hypertens (Greenwich). 2002;4(6):393-404.

82. Turnbull F. Effects of different blood-pressure-lowering regimens on major cardiovascular events: results of prospectively-designed overviews of randomised trials. Lancet. 2003;362(9395):1527-1535.

83. Yarows SA, Oparil S, Patel S, Arora V, Zhang J. Aliskiren in combination with valsartan provides additional blood pressure-lowering effects compared with either agent alone in elderly and younger patients with hypertension. J Hypertens. 2008;26:S19-S20.

84. Yarows SA, Oparil S, Patel S, Fang H, Zhang J. Aliskiren and valsartan in stage 2 hypertension: subgroup analysis of a randomized, double-blind study. Adv Ther. 2008;25(12):1288-1302.
Vascular Health and Risk Management

\section{Publish your work in this journal}

Vascular Health and Risk Management is an international, peerreviewed journal of therapeutics and risk management, focusing on concise rapid reporting of clinical studies on the processes involved in the maintenance of vascular health; the monitoring, prevention and treatment of vascular disease and its sequelae; and the involvement of

\section{Dovepress}

metabolic disorders, particularly diabetes. This journal is indexed on PubMed Central and MedLine. The manuscript management system is completely online and includes a very quick and fair peer-review system, which is all easy to use. Visit http://www.dovepress.com/ testimonials.php to read real quotes from published authors. 